\title{
EMBEDDING SOFT SKILLS WITHIN LEARNER-CENTRED ENVIRONMENTS FOR VOCATION EDUCATION GRADUATES
}

\author{
Tracey Carlyon and Amy Opperman
}

\section{INTRODUCTION}

In Aotearoa New Zealand, like many other countries, Institutes of Technology and Polytechnics (ITPs) play an integral role to ensure the workforce are educated for the future. This requires that graduates are 'work ready' and have the necessary qualifications and skills required by employers to make a productive contribution to industry. While a vocational qualification requires the development of hard skills, it has become increasingly evident that soft skills are equally important to enhance a graduate's employability. As such, education providers must respond to this need by ensuring their programmes engage and prepare their learners for the future (Snape, 2017). As an ITP, Waikato Institute of Technology (Wintec) recognise this and are committed to ensuring students have opportunities to develop their soft skills within learner-centred environments. This is reflected in Wintec's Ako Teaching and Learning Directions, which provides the basis for "ensuring our students develop critical abilities, skills, knowledge, values and attitudes to be successful in education, work and life" (Wintec, n.d.). One of the key principles of the framework is learner-centredness, which includes teaching practice that engages students; includes explicit skills instruction; encourages students to self-reflect; motivates students and encourages collaboration.

This article reports on research designed to learn more about how tutors from ITPs approach the development of students' soft skills within their teaching curricula. A case study approach grounded in interpretive methodology, which describes and interprets social situations (Mutch, 2005), was considered appropriate for the research. As Cohen, Manion and Morrison (20II) suggest, a case study focusses on portraying "participants' lived experiences of, thoughts about and feelings for a situation" (p. 254). For the research, five highly effective tutors from across Wintec's vocational education programmes were invited to participate in semi-structured interviews in August 2019. The disciplines in which these participants taught included information technology (IT), culinary arts, media arts, nursing, and early childhood education. Pseudonyms have been used to protect the anonymity of these participants. During each interview extensive field notes were taken, which were later analysed for common words and themes. The research was based around the following two research questions:

I. What do tutors consider to be important soft skills for their students to develop in order to be work ready?

2. What are the different ways tutors embed opportunities for their students to develop these soft skills?

The next section explores some of the current literature which is focussed on soft skills. This is followed by a summary of the findings from each of the five case studies. A discussion, including a framework, designed by the authors, to demonstrate how tutors embed soft skills is presented, followed by a conclusion.

\section{SOFT SKILLS}

Sometimes referred to as 'employability' skills, soft skills are considered to be the behaviours, attitudes and personal qualities that are essential for gaining and retaining employment (Tertiary Education Commission, 2020). While it 
is difficult to define or measure these types of skills, it has been suggested that soft skills include communication, social skills, higher-order thinking, self-control and positive self-concept (Lippman, Ryberg, Carney, \& Moore, 20I5). Soft skills can also be defined as the four C's - creativity, collaboration, communication and creative thinking (Green \& Blaszczynski, 20I2). Furthermore, while referred to as values and key competencies, New Zealand curricula identifies skills such as inquiry, curiosity, integrity, managing self and relating to others as important for our learners to develop (Ministry of Education, 2007). While soft skills differ to technical, or hard skills it has become increasingly evident that employees need both types of skills in order to gain employment and make a productive contribution to industry. This is evident in the IT industry where many employers are currently reported to be less concerned with technical skills and are recruiting employees who have the soft skills they specifically require (Stevens \& Norman, 2016). This has created much debate about which soft skills are important to develop, how much attention should be given to developing them and how this can occur alongside hard skills development.

In Aotearoa New Zealand, there are resources specifically designed for supporting tutors to develop their students' soft skills. For example, Guidelines: Strategies for Teaching Employability Skills in Vocational Programmes is provided by Ako Aotearoa (Duignan et al., 20I8). This resource comprises a toolkit of ideas and strategies to support vocational education tutors to embed employability, or soft skills, into their practice. A further example is the Youth Guarantee Vocational Pathways for Education Providers (Ministry of Education, n.d.) which outlines three principles underpinning vocational pathways programme design, including how tutors can ensure programmes of learning are student centred. Although these resources provide some support, generally in ITPs in Aotearoa New Zealand it is up to individual tutors to decide which soft skills they consider to be important and how they choose to teach these.

Research confirms that many vocational education tutors deliberately embed opportunities for students to develop soft skills within curricula (Fraser, Duignan, Stewart, \& Rodrigues, 2019). These authors explain how tutors do this "both overtly and covertly, using a myriad of approaches and strategies which fit seamlessly within their delivery of core curriculum content" (p. 170). Others agree that making explicit links to those skills which relate to employability is essential in order that students can recognise and adopt them (Green \& Blaszczynski, 2012). Further to this, Cranmer (2006) suggests the approach of explicitly embedding and integrating soft skills has a higher impact than teaching them through modelling without making explicit links or teaching them in separate courses. "Meaningful learning of these 'soft skills' will occur best in authentic and integrated programmes where explicit teaching identifies the required learning" (Snape, 20I7, p. I). These types of programmes align with learner-centred environments and teaching, which also include explicit skill instruction as well as encouraging reflection; collaboration and motivating students by giving them greater control over their learning (Weimer, 2012). As this author explains, in learner-centred environments tutors are designers and facilitators of learning experiences that focus on the development of learning skills and learner self-awareness (Weimer, 2002).

Despite this literature, feedback from industry continues to identify that a gap exists between industry expectations and graduate work-readiness. Employer engagement groups (EEGs) who regularly meet with ITPs have for some time emphasised soft skills as being equally as important as hard skills. Furthermore, some industries are now seeking graduates with a particular set of soft skills, rather than hard skills, which are thought to be more easily developed in the workplace. Therefore, it is necessary to learn more about how tutors from different disciplines within ITPs approach the development of students' soft skills within their teaching curricula.

\section{FINDINGS}

The findings are presented in a summary from each of the five case studies. Aligned with Wintec's Ako Teaching and Learning Directions, the tutors interviewed all demonstrated learner-centred approaches including encouraging students to take responsibility for, and reflecting on, their own learning. They all described examples that demonstrated how opportunities for the embedding of soft skills development occurred both explicitly and implicitly. This practice of embedding soft skills alongside hard skills development is supporting Wintec students' future employability. 


\section{Interview I: Mary - Information technology}

Mary teaches IT programmes with a large majority of her students being male, ranging from 18 to 21 years. The soft skills Mary identified as being most important for her students to develop were encapsulated within the following four areas: being professional; relational; able to problem solve; and having a good understanding of oneself. Being professional included punctuality, personal presentation and showing a positive attitude about tasks one may be asked to carry out. Being relational is a soft skill that Mary also believes is very important and explicit links are made to the importance of working together in positive ways. She is also committed to building and sustaining positive relationships with all her students, which provides modelling of this soft skill. Teaching self-awareness to students, or having a good understanding of oneself, is something Mary considers an important soft skill. This includes her students learning about their personal learning style, so they take more responsibility for their own learning and build confidence to take risks.

A clear strategy used by Mary to teach problem solving is humour, as she explained: "I use humour a lot to teach soft skills as it helps put them [students] at ease." One example of how Mary uses humour is when a student asks her to identify their errors she responds with "Who did the typing?" followed by "I bet you $\$ 500$ I can spot the mistake." This fun approach is twofold as Mary explained, it takes the students attention away from the screen to refresh their thinking after which they are usually able to identify their own error. Furthermore, she supports her students by requiring them to document, in their own diary, all coding/error messages to help identify patterns for future reference. Mary explained that being able to problem solve involves teaching strategies to break down problems into steps and is relatively easy to incorporate within her discipline of IT. The variety of teaching tools Mary deploys to enhance and draw on the development of soft skills alongside hard skills includes embedding videos and slide shows, drop and drag games, Kahoots quiz (game-based learning platforms), and video scribe.

Mary is clearly very passionate about teaching and committed to building positive, trusting relationships with her students. This was evident as she explained how she emails students to ask how she can support them, provides additional classes in the weekends for those who required it and has a genuine commitment to giving detailed and timely feedback to her students. Clearly Mary is proficient at explicitly embedding opportunities for soft skill development within the learner-centred environments she establishes and innovative teaching practices she creates.

\section{Interview 2: Carl - Culinary arts}

Carl teaches in the culinary arts programme in which there are several international students. He identified the following soft skills as being important for students to develop: professionalism; teamwork; stress management and being reflective. Professionalism includes punctuality, time management, developing routines and taking responsibility for one's own learning and actions. As such, students identifying and taking responsibility for their errors is something that is focussed on a lot in class. Particular attention is drawn to punctuality as Carl considers this crucial to the culinary arts industry. He explained how he always starts his classes on time and whenever a problem occurs that relates to the workplace, he is deliberate about stopping and making the connection for the students.

Teamwork is another important soft skill that Carl pays attention to and he explained that alongside teaching the curricula he talks about how teams need to work together and help each other out. When the students do not work as a team, or he observes one student leaving others to clean up, he stops the lesson and talks about what would happen in the industry if this occurred. He explained: "I encourage my students that if they see a job to step up and do it." Carl also values the skill of being able to manage stress, as his industry can be a high stress environment to work in. In addition to teaching conflict resolution strategies and how to manage stress, Carl takes care to work in a calm manner himself. He believes it is important for students to learn that there are consequences for every action and stress management is an essential skill to have in his industry. 
An important part of the culinary arts programme is for students to develop an individual digital portfolio (known as an electronic portfolio), which can be considered a resume, in order to demonstrate their soft and hard skills. This requires students after every lesson to use their own device to record evidence of their best product, the process, and how they are taking responsibility for their own learning. Carl explained that reflective writing is a big part of culinary arts and he supports students through this process so they can self and peer assess and make comments that are fair and constructive.

Carl also draws on storytelling, using real life scenarios and humour to embed opportunities to develop soft skills within his programmes and at every opportunity makes connections to reinforce the soft skills required to work successfully in the culinary arts industry.

\section{Interview 3: Sally - Media arts}

Sally, who teaches in a range of programmes within media arts, identified communication as being one of the key soft skills for students to develop, in addition to time management, teamwork, punctuality and empathy. Sound communication skills include being able to express oneself concisely and appropriately and involve both verbal and non-verbal methods (such as electronic messages). Sally explained that good time management skills are important to develop as working in many areas of the media arts industry require estimating how long tasks may take and calculating costings accurately.

Punctuality is considered by Sally to be an essential skill and she talks to her students about why being on time is so important and how this applies in the workforce. She makes explicit links to time management, being punctual and is quite strategic about starting her classes with fun games and activities as a motivator for students to be on time. She feels that because of this her students are rarely late to class and those who are, tend to apologise for being so. This is linked to having empathy and respect for others and Sally explained she would never embarrass a student about any concern she may have. Instead she would think carefully about having a private conversation to solve any issues in a respectful manner. Having empathy with others is a skill Sally considers is becoming increasingly useful to develop. As her students are becoming more culturally diverse and sometimes less mature than previous cohorts, it is important that they all learn how to understand and support others. A useful activity Sally practices to support this is undertaking personality profiles with her students, which she finds works well as they learn how others see things differently.

One way in which Sally's students can gain an understanding of which soft skills employers are seeking in the media arts industry is by analysing employment advertisements and then writing cover letters, resume, and undertaking presentations. She explained that "we are aiming for them [the students] to be able to present themselves to industry in a positive light as the person they are and what they have to offer." Games and ice breakers, which require her students to work together and communicate effectively, are explicitly embedded into her classes to support students with building skills including communication, teamwork and empathy. Furthermore, activities such as writing timelines, analysing assessments, planning projects and group tasks all provide scaffolding for students to be able to work together successfully on team projects. Attention is drawn to the learning outcomes at the beginning and end of teaching sessions to help students make connections to soft skills. All the activities and tasks Sally includes are enhanced through students writing short reflections. The students are supported through the process of reflective writing and for those who require it, a framework is provided.

Sally acknowledged a shift that has occurred in the design industry whereby employers are often seeking students who have certain soft skills as opposed to technical skills. In addition, she noted that because her students are frequently surprised by this, it is important to be explicit when teaching these skills. 


\section{Interview 4: Leanne - Nursing}

Relationality, as opposed to soft skills, is a term Leanne suggests is more aligned to nursing. She considers the term soft skills could be interpreted as being unimportant and explained how in nursing "we look at and talk about relationship skills, and this connects to the caring nature." Leanne described how relationality within the discipline encompasses nurses valuing and working with others. Furthermore, relationality involves considering individual values, building rapport, being genuine around others and establishing authentic relationships. Leanne pointed out "some people could call it an ethical phase" and outlined that because society gives nurses trust it is important to honour this. In addition to trust, encompassed within relationality is having self-awareness, working together, communicating effectively, respect and demonstrating competencies such as punctuality, a clean uniform and not wearing jewellery, which are essential for nursing students.

Opportunities for students to develop relationality are provided through role modelling, establishing group contracts, discussions and most importantly engaging in self-reflection. Leanne believes role modelling relationality is an essential part of teaching nursing and she takes care to get to know her students, takes a genuine interest in them and shows respect. Additionally, she models positive communication skills including not talking over others and taking particular care with wording emails and electronic messages such as in Moodle. In class, students are required to engage in activities that focus on what Leanne refers to as 'ways of being' which require students to share what is important to each of them and then unpack these ideas together. This and other activities are designed to show how students can build respect, work together effectively and communicate positively.

Students are taught how to write self-reflections and consider their own actions and responses in different situations that may arise when out on placement. Placement is integrated into the nursing programme to enable students to gain work experience, including the opportunity to practise further and to develop the hard and soft skills learned in class. These oppportunities make the step from study to work as seamless as possible for students.

Leanne highlighted how her student nurses are supported, both in class and on placement, to develop self-awareness and reflection skills with a framework that has been adapted specifically for nursing and are given feedback on their reflections. She also explained that having self-awareness, seeing themselves as others see them and becoming critically reflective is fundamental to nursing.

\section{Interview 5: Kirsten - Early childhood education}

Kirsten, like Leanne, does not use the term 'soft skills'-but instead prefers 'dispositions' or 'attitudes and attributes' that can be learnt. She explained that dispositions, of both teachers and children, are considered a lot in early childhood education and are an integral part of Te Whäriki, the Early Childhood curriculum. She identified a range of professional behaviours that are important to have when working in early childhood education such as: taking initiative; developing time management and ethical relationships; respecting diversity; behaving in a collegial, reflective, and curious manner; and persevering.

Kirsten talked about the importance of punctuality and students developing the skill of critical reflection. Explicit links are made to being on time when working in early childhood education centres and discussions about how this impacts others, including young children, parents and colleagues. She explained that students having the ability to reflect and discuss how they interact with others helps them to learn how to give and receive feedback respectfully over time and develop resilience. Kirsten outlined how opportunities to develop reflection skills are provided explicitly through writing reflections and engaging in class discussions "so students can talk through what "best practice' can look like." In addition, she described her classes as being "very relational" where the students talk a lot about responsive, reciprocal relationships and what these mean within early childhood education. 
Along with class activities, further opportunities are provided in field-based practice for students to develop dispositions such as relationship building and using their initiative which are essential in early childhood education. Field-based practice is included within the programme for students to work two days each week in a centre to learn how to integrate theory in practice. This field-based practice provides authentic opportunities for students to work with young children, collaborate with others and includes visits and observations carried out by tutors such as Kirsten. Students have certain tasks to complete when working in centres such as writing self-reflections and engaging in a project based around an inquiry.

\section{DISCUSSION}

These findings show that the tutors all believed it was essential for their students to develop certain soft skills in order to be work ready. While two tutors preferred relationality and dispositions to the term 'soft skills', the type of skills they identified as being important for students to develop were similar to and aligned with previous research (Green \& Blaszczynski, 20I2; Lippman et al., 20I5). Furthermore, despite the different disciplines, many of the skills identified by the tutors were interrelated and could be encompassed within the following four categories: relational, professional, reflective, and effective communication. Being relational included showing respect and empathy while being able to form and sustain positive, collegial, responsive relationships with others. This was closely linked to having the ability to work well in a team while being cognisant of others and their differences. Professionalism included punctuality, which all tutors discussed at length, in addition to personal appearance, positive attitude and behaving ethically. Being reflective was identified as an essential skill to develop self-awareness, self-responsibility and resilience. Finally, having effective communication skills, both verbal and non-verbal, were considered important for students to develop in order to work effectively with others and enhance their employability.

The tutors described a variety of strategies they used to embed opportunities for their students to develop these soft skills including storytelling, humour, role modelling, targeted activities, and making use of teachable moments. Aligned with previous research, (Fraser et al., 2019) the five tutors interviewed showed how they made both explicit and implicit links to the soft skills being developed. Storytelling provided authentic examples to help students develop self-awareness and learn the importance of taking responsibility. Sometimes used within storytelling to gain impact, humour was also used to build positive relationships. Role modelling was another effective method to demonstrate the importance of soft skills such as being punctual, developing positive relationships with others and again taking responsibility. Targeted activities, such as how to write useful reflections, supported students to learn about themselves, how to work effectively with others and provided opportunities to prepare students for recruitment into the workforce. Finally, making effective use of teachable moments offered authentic learning opportunities that linked explicitly to industry in order to develop soft skills. 


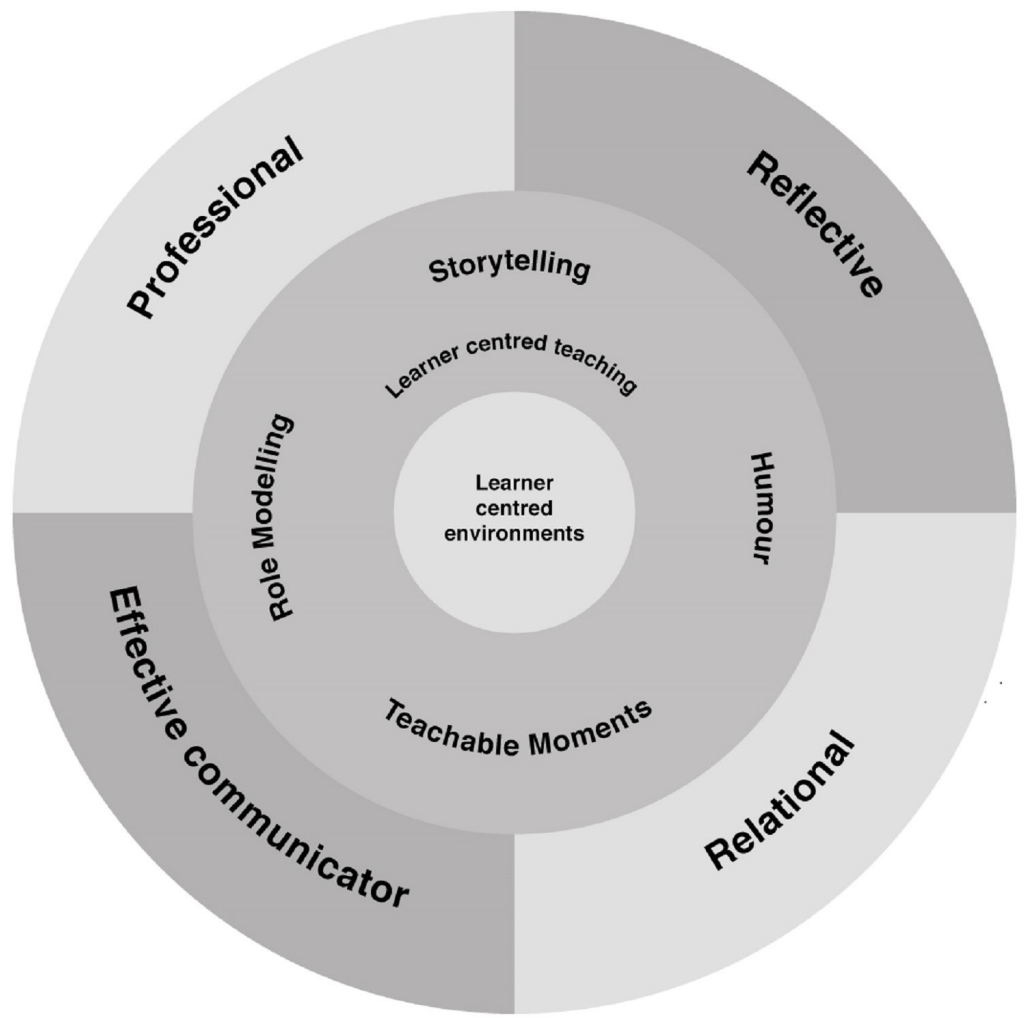

Figure I. The development of students' soft skills within learner-centred environments.

Source Carlyon and Opperman.

Figure I, developed by the authors, illustrates the connection between the learning environment, teaching and learning strategies, and soft skills. At the heart of the framework sits learner-centred environments which are established from embedding a range of learner-centred teaching strategies that include explicit skills instruction, as well as to engage, motivate, and encourage students to self-reflect and collaborate. In turn, as shown in the outer circle, these strategies provide opportunities for students to develop the essential soft skills they require in order to be work ready.

\section{CONCLUSION}

Findings from the research reported on in this article align with previous literature (Fraser et al., 2019; Green \& Blaszczynski, 2012) which suggests soft skills can be successfully and deliberately embedded into vocational education curricula. Tutors from across a range of disciplines show they have a sound understanding of the skills required by industries and are adept at engaging creative and varied teaching strategies to ensure their students have opportunities to develop these skills. In alignment with Wintec's Ako Teaching and Learning Directions framework (Wintec, n.d.), the strategies employed by tutors create learner-centred environments to enable students to become independent, employable graduates. While at times the links to soft skills are implied, tutors frequently make these explicit for their students in order to illustrate the importance of those skills that relate to industry. This practice of embedding soft skills alongside hard skills development within learner-centred environments supports Wintec students' future employability. 
Dr Tracey Carlyon is a Teaching and Learning Coach at Wintec. She has teaching and leadership experience in primary schools and also in teacher education at The University of Waikato. She has published widely on the topic of teacher transitions, how these impact personal and professional identity, and learning.

Amy Opperman is a Teaching and Learning Coach at Wintec. In this role, she provides support for tutors across Wintec around their practice, pedagogy and professional learning. Amy also has extensive experience in product development at Wintec and has worked with project team members to ensure programmes are well developed.

\section{REFERENCES}

Cohen, L., Manion, L., \& Morrison, K. (20II). Research methods in education (7th ed.). Routledge/Falmer.

Cranmer, S. (2006). Enhancing graduate employability - best intentions and mixed outcomes. Studies in Higher Education, 31 (2), 169-184. https://doi.org//0.1080/03075070600572041

Duignan, G., Casley, S., Fraser, C., Haggerty, C., Hannam, S., Hitchcock, J., Rodrigues, A., Ross, K., Seno, L., Stewart, D., Taylor, B., \& Webster, A. (2018). Teaching strategies that build employability skills of vocational education graduates [Project report]. Ako Aotearoa.

Fraser, C. J., Duignan, G., Stewart, D., \& Rodrigues, A. (2019). Overt and covert: Strategies for building employability skills of vocational education graduates. Journal of Teaching and Learning for Graduate Employability, 10(1), I57- 172.

Green, D., \& Blaszczynski, B. (2012). Effective strategies and activities for developing soft skills, Part I. Journal of Applied Research for Business Instruction, 10(I), I-I4.

Lippman, L. H., Ryberg, R., Carney, R., \& Moore, K. A. (2015). Workforce connections. Key "soft skills" that foster youth workforce success: Toward a consensus across fields (Child Trend Publications). United States Agency for International Development (USAID). Office of Education.

Ministry of Education. (n.d.). Vocational Pathways for Education Providers. http://youthguarantee.education.govt.nz/tools/educators/ Ministry of Education. (2007). The New Zealand Curriculum. Learning Media.

Mutch, C. (2005). Doing educational research. A practitioner's guide to getting started. NZCER Press.

Snape, P. (2017). Enduring Learning: Integrating C2Ist soft skills through technology education. Design and Technology Education: An International Journal, 22(3), 48-59.

Stevens, M., \& Norman, R. (2016). Industry expectations of soft skills in IT graduates. Australasian Computing Education, 2(5). https://doi.org/l0.1145/2843043.2843068

Tertiary Education Commission. (2020). Skills employers are looking for. https://www.careers.govt.nz/plan-your-career/get-ideasfor-your-career/skills-employers-are-looking-for/\#cID_7983

Weimer, M. (2002). Learner-Centred Teaching. Jossey-Bass W Wiley Company.

Weimer, M. (20I2). Learner-centered teaching and transformative learning. In E W Taylor \& P Cranton (Eds.), Handbook of transformative learning: Theory, research, and practice (pp. 439-454). Jossey-Bass.

Wintec. (n.d.). Ako: Teaching and Learning Directions 2017-2020. www.wintec.ac.nz. https://wintec.ac.nz 